\title{
The Formation of a Safety Ecosystem in the Context of Ensuring the National Homeland Security
}

\author{
Oleksandr Polishchuk ${ }^{1 *}$, Yulia Bobrova ${ }^{2}$, Yuriy Bobrov ${ }^{3}$ \\ ${ }^{1}$ National Institute for Strategic Studies, Kyiv 01054, Ukraine \\ ${ }^{2}$ Taras Shevchenko National University of Kyiv, Kyiv 01033, Ukraine \\ ${ }^{3}$ Legal Service of the Armed Forces of Ukraine, Ivano-Frankivsk 59089, Ukraine
}

Corresponding Author Email: polishchukoleksandr19@gmail.com

https://doi.org/10.18280/ijsse. 110608

Received: 14 November 2021

Accepted: 12 December 2021

\section{Keywords:}

ecosystem, national security, state, homeland, model

\begin{abstract}
Today, the issue of creating conditions for homeland security is relevant, under which any socio-economic system can be comfortable and is not threatened by the negative influence of any external and internal factors. The main purpose of the study is to form a methodological approach to the formation of an appropriate defense ecosystem in the context of ensuring homeland security. To achieve this goal, we applied analysis and synthesis methods to study the current state of the homeland security level and the methodology for the formation of the IDEF0 functional model to represent the proposed defense ecosystem. The methodological approach can have the practical importance for state structures dealing with the issue of ensuring homeland security. The result of the study was the formation of a decomposition of the first, second and third levels of the functional model of the defense ecosystem in the context of ensuring homeland security. The article has limitations which are associated with the choice of the security system of Ukraine, since in the context of a pandemic, it was difficult to gain access to information from other countries. In the future, the proposed methodological approach is planned to be applied to the homeland security systems of other countries.
\end{abstract}

\section{INTRODUCTION}

A characteristic feature of modern world development is the intensification of transnational processes taking place in the material and spiritual spheres of social life. In such conditions, more and more attention is attracted by global problems, which, touching humanity as a whole and each state (society), in particular, concentrate on the contradictions of social development. The cardinal geopolitical changes taking place at the beginning of the 21 st century indicate that the world has entered the phase of another global transformation. Since the early 90s, the modern world has been living in unusual conditions of transition to polycentricity, the formation of which is accompanied by an exacerbation of economic, geopolitical, ethno-confessional, demographic, and other contradictions between the centers of power and world civilization.

The twentieth century was unable to ensure peace on the planet. On the contrary, it constantly demonstrated the growth of confrontation between the two then existing antagonistic socio-political systems. But self-destruction of one of the components of the bipolar world order did not lead to peace. On the contrary, having lost its equilibrium point during the collapse of bipolarity, civilization was faced with an increase in conflicts caused by the collision of vital fundamental state interests of the leading countries of the world and the emergence of a system of newest threats to their preservation. Reality requires a fundamentally new philosophical approach to understanding emerging situations. This is especially important for transitional societies reviving statehood. The process of statehood formation is associated with the need to ensure reliable homeland security. Today, there are no stable scientific stereotypes of reflection on the phenomenon of homeland security, therefore, it is vitally important for almost all societies to substantiate this phenomenon and to orient the domestic and foreign policies of states accordingly. This is of particular importance in the context of sociocultural transformations. The duration and effectiveness of transformation processes, the normal historical development of societies, while maintaining national identity, depends on the degree of adequacy of such substantiation. The existence of any sovereign state is impossible without protecting its national interests, which is the main, fundamental condition for guaranteeing self-preservation and progressive selfdevelopment of society. For such reasons, the homeland security of transitional societies is the primary condition for a successful socially organized life.

Protecting sovereignty, ensuring territorial integrity and inviolability of state borders, restoring its territorial integrity, reintegrating temporarily occupied and uncontrolled territories, and restoring peace are the priority tasks of state policy to ensure homeland security, the solution of which is possible only under the condition of effective interaction and wellcoordinated work of all stakeholders. facilities both nationally and internationally. Achievement of certain goals requires a qualitatively new state policy aimed at the effective implementation of homeland security, comprehensive reform of the public administration system for its provision, and the creation of an effective ecosystem of turnover, a new foreign policy positioning in the world amid the instability of the 
global security system. To achieve this, it is necessary to form a clear security system and take into account the interests of all parties to the conflict. The existing system should have a clear goal and task of how to achieve it.

Protecting your territory is not an easy task. A real example, today is the situation in Ukraine, where, due to the aggression of the Russian Federation, we observe a conflict in certain territories of Ukraine and a threat to its territorial integrity.

Today, a proper defense ecosystem in the context of ensuring the security of one's territory and the state as a whole is a relatively stable, organized, and purposeful activity of existing state institutions, which is carried out by them directly or indirectly about the existing problems in this area, or a set of problems that are influenced real or potential threats. It is a means that allows the state to achieve a certain goal in specific circumstances, using legal, economic, and administrative methods of influence, relying on the resources at its disposal.

The study of the process of building a defense ecosystem in the field of ensuring the security of the state as a whole is a rather difficult task, which is due to a significant number of its aspects, among which one of the main places is occupied by the tasks of ensuring the protection of individuals and society. Consideration of the results of scientific research on homeland security issues indicates that the most significant groundwork was made by scientists of the twentieth century when there was a rethinking of the very nature of security and practical policy in this area.

The defense ecosystem as a whole should contribute to improving the effectiveness of the security policy and to the coordination of the activities of the authorities, the creation of the necessary structures in the homeland security system, the initiation, and holding of public discussions on security issues, and the legislative approach, which is disclosed through ensuring homeland security through the adoption of new legislative norms and various forms of government control.

The main goal of the study is to form a methodological approach to the formation of an appropriate defense ecosystem in the context of ensuring homeland security.

\section{LITERATURE REVIEW}

A significant number of works are devoted to the problems and features of safety - from ancient philosophy to modern scientific developments. In modern scientific literature, in particular in the literature on social philosophy, significant material has been accumulated, certain theories and concepts of homeland security have been formed, various approaches to determining its essence, the formation of a system for ensuring homeland security and its functioning have been identified and formalized. The investigated problem attracts considerable attention of domestic and foreign researchers in various fields of social knowledge - philosophy, political science, sociology, social psychology. The problem of homeland security has acquired a special degree of development due to its directly practical nature within the framework of political science. Taking this into account, it is possible to single out several groups of works that meet a specific structure of research needs.

It should be noted that the 20th century experienced many conflicts during its period, and it is on the basis of scientific research of this era that a scientific and practical basis for researching the problems of ensuring homeland security is being formed today.
The problem of security at the present stage of the development of socio-humanitarian knowledge attracts the attention of domestic and foreign researchers in various fields - philosophy, political science, sociology, theory of public administration. And the term security itself has become very popular in recent years and is used so widely and comprehensively that it is quite often impossible to single out the essence and boundaries of application of the main components of security concepts and categories.

Security issues have always been the focus of many scientists and practitioners in the field of security as such. Today we can talk about a significant contribution to the development of solutions to security problems of economic nature for the state [1] and, for example, Borodzicz [2], how important is the corporate level of security.

One cannot but take into account the basic elements of the concept of security itself and how important it plays a role. Baldwin [3] has dealt with this issue.

Of course, the approach proposed by us includes the modeling apparatus that was applied in certain aspects of security. This is evidenced by the studies of Kryshtanovych [4, 5], but they relate more to the microlevel and certain areas of security. This is all new to building a defense ecosystem.

What aspects of ensuring security at the global level should be taken into account should also be investigated in detail [6].

It is impossible to form a proper environment for ensuring homeland security and native land without an appropriate system of protection and counteraction to modern threats. As Patel notes [7], this is the basis for any security system as such.

We are building our research, taking into account the main aspects and areas through which a high level of state security and a proper defense system is achieved. This is well documented in the works of Balzacq [8] and others [9, 10].

By the term "homeland security" we mean an indicator of the ability of society and the state, protecting national interests, independently or together with other friendly countries (peoples, nations), to contain or eliminate internal and external threats to national sovereignty, territorial integrity, social order, economic development, other important elements of spiritual and material life; the degree of protection of the interests of the individual, society and the state from external and internal threats. Ensuring homeland security is facilitated by the peaceful nature of the relationship of the state (people, nation) with other states (peoples, nations). Strengthening homeland security consists in creating the conditions necessary for the reliable protection of the interests of the state and the nation and the successful solution of the political, economic, social, and other tasks that they face.

Paying tribute to a large number of studies in the field of security, today the process of forming a methodological approach to the formation of an appropriate defense ecosystem in the context of ensuring the homeland security needs to be actively worked. The main reason for choosing this topic is the fact that in matters of security, individual mathematical methodological approaches are very rarely used, which would be available and open for clarification. There are few scientific ones devoted to this aspect, and that is why we decided to choose this direction.

\section{METHODOLOGY}

The formation of an appropriate ecosystem needs to counteract the negative factors of ensuring homeland security. 
Factors and their negative impact occur in different areas of homeland security. For example, this can relate to social security or the political sphere. There are a lot of components influencing the state of the ecosystem of the social system security, but they can be reduced to the following groups: economic, political, military, and protection of the population.

To form a methodological approach to the formation of an appropriate defense ecosystem in the context of ensuring homeland security and the state as a whole, we will apply the IDEF0 functional modeling methodology.

Describing a system using IDEF0 is called a functional model. The functional model is intended to describe existing business processes in which both natural and graphical languages are used. For the transfer of information in a specific system, the source of the graphic language is the IDEF0 methodology itself.

The IDEF0 methodology prescribes the construction of a hierarchical system of diagrams - single fragments of the system are described. First, the system as a whole and its interaction with the outside world are described (context diagram), after which functional decomposition is carried out - the system is divided into subsystems and each subsystem is described separately (decomposition diagrams). Then each subsystem is broken down into smaller ones, and so on until the desired level of detail is achieved.

IDEF0 requires that the diagram contains at least three and no more than six blocks. These constraints maintain the complexity of diagrams and models at a level that is readable, understandable, and useable. In our case, this value will be four blocks. This makes it possible not to complicate the volumes of information received (for expansion, new decompositions are used) and, thanks to the restriction, it is possible to form an integral model that does not overload information and blocks.

Table 1. Key input data for the formation of a functional model (developed by authors)

\begin{tabular}{cc}
\hline Name & Feature \\
\hline $\begin{array}{c}\text { The purpose of } \\
\text { modeling }\end{array}$ & $\begin{array}{c}\text { Develop a methodological approach to the } \\
\text { formation of an appropriate defense ecosystem in } \\
\text { the context of ensuring the homeland security }\end{array}$ \\
$\begin{array}{c}\text { Target } \\
\text { audience of the } \\
\text { model }\end{array}$ & security subjects \\
$\begin{array}{c}\text { Context of the } \\
\text { model }\end{array}$ & list of functions and objects of diagrams \\
Software & vector diagramming application \\
\hline
\end{tabular}

A0 - Defense and security

Al- Formation of mechanisms for ensuring military defense

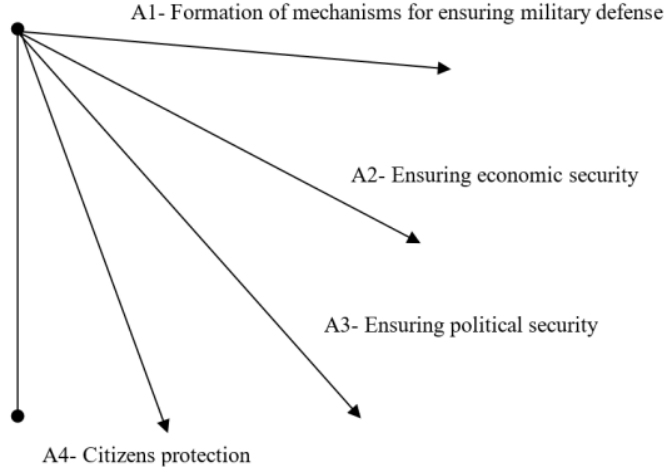

Figure 1. Hierarchy of blocks of the IDEF0 functional model of the formation of a defense ecosystem in the context of ensuring homeland security (developed by authors)
Key input data for the formation of our functional model is shown in Table 1.

To begin with, it is necessary to form a context diagram of the highest possible level, and this affects A0 for our IDEF0 model.

Let's build a tree of nodes, a list of functions and objects with appropriate explanations will become the initial basis for their creation (Figure 1).

The results of the application of the proposed products, our methodology, can be seen in the next section.

\section{RESULTS OF RESEARCH}

So, applying the proposed IDEF0 functional modeling methodology to form a defense ecosystem in the context of ensuring homeland security, we will build a complex diagram of the model itself.

It should be noted that all blocks A1-A4 carry out the process of converting input to outputs through certain mechanisms. So, we will designate the whole system by block A0 itself. Thus, all inputs, outputs, controls, and mechanisms will be connected to the block by limit arrows and codes.

So, in Figure 2 there are several basic mathematical symbols and designations that are aimed at achieving the main task - to form a defense ecosystem in the context of ensuring homeland security. So, input $-I_{n}(n=1,2)$, control $-C_{n}(n=1,2)$, output $-\mathrm{O}_{\mathrm{n}}(\mathrm{n}=1,2)$, mechanism $-\mathrm{M}_{\mathrm{n}}(\mathrm{n}=1,2)$.

The first result in the process of our modeling will be the formation of the first level decomposition.

The elements of the decomposition of the first level of the context diagram of the IDEF0 model of the defense ecosystem in the context of ensuring homeland security include:

A1- Formation of mechanisms for ensuring military defense - the creation of effective mechanisms and implementation of comprehensive measures to prevent possible aggression or military conflict, localize and eliminate their consequences; prevention of attempts and elimination of violations of the state border of the territorial integrity; democratic civilian control over the military organization of the state.

A2- Ensuring economic security, which contains measures to prevent the illegal use of budget funds and state resources, their overflow into the shadow economy; control over exportimport activities aimed at supporting important priorities for Ukraine and protecting the manufacturer; combating existing illegal economic activity, countering the uncontrolled outflow of national material, financial, intellectual, information and other resources.

A3- Ensuring political security, which includes the creation of effective mechanisms to protect the rights of citizens in the state and in the world; prevention and elimination of attempts to interfere in the internal affairs; joining the existing and emerging systems of universal and regional security; To avoid political extremism, support civil harmony and social stability; building a reliable system for protecting constitutional principles, preventing and combating violations of law and order, creating the necessary conditions for an effective fight against corruption and crime, especially its organized forms; ensuring the proper implementation of legal decisions of state authorities and local self-government. These are just some of the ways that, in our opinion, we propose to ensure the political in the context of our research and the established model. The flexibility of the model allows the elite and others, but as an example and demonstration, we offer these ways to ensure political security. 


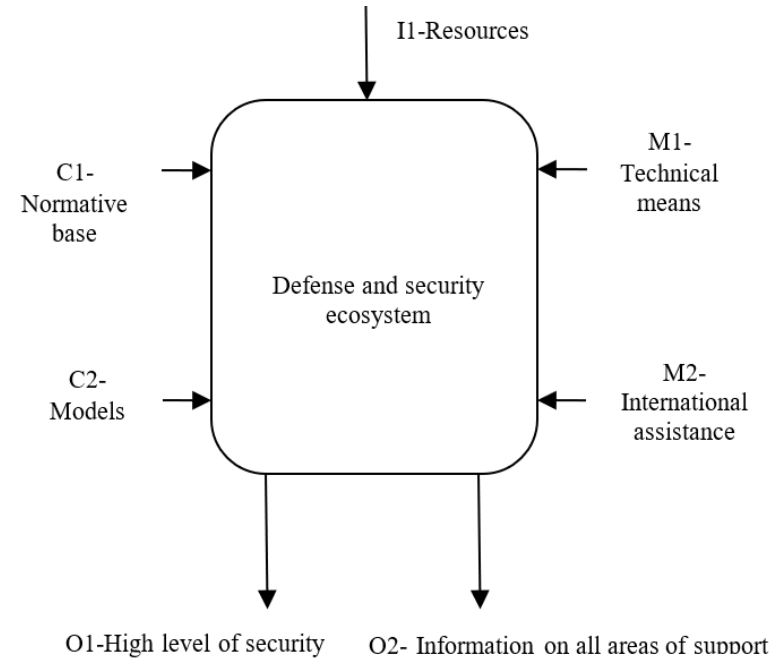

Figure 2. Comprehensive diagram of the model IDEF0 formation of a defense ecosystem in the context of ensuring the homeland security (developed by authors)

A4- Citizens protection, which includes identifying and eliminating the causes leading to a sharp stratification of society during the transition to a market economy; taking timely measures to counter the crisis demographic processes; creation of an effective system of social protection of a person, protection and restoration of his physical and spiritual health; stimulating the development and ensuring comprehensive protection of the educational and cultural potential of the country; professional consumer protection.

As a result, all the elements and the correct application of our proposed methodology allow us to represent, the decomposition of the first level of the context diagram of the model IDEF0 formation of a defense ecosystem in the context of ensuring the homeland security. This decomposition is shown in Figure 3.
Decomposition of the former does not mean that it may be the last and only model. Variants with detailing of any of the processes A1, A2, A3, or A4 are possible.

For clarity, we will present the details of the A2 process ensuring economic security. Sub-processes for detailing this process include: A21-Effective and targeted use of budget funds. A22-Counteraction to the shadow economy. A23Investment protection in the economy. This decomposition is shown in Figure 4.

So, as a result of our research, we proposed a methodological approach that allows us to reflect on the main processes of the formation of a defense ecosystem in the context of ensuring homeland security.

For even better detail, let us choose from Figure 4 subsystem A22-Countering the shadow economy to demonstrate the decomposition of the third level (Figure 5). Countering the shadow economy should include improving the legal framework and tax relief.

\section{DISCUSSIONS}

Discussing the results of our study, it should be noted that, as Zender noted [11], several conceptual foundations and safety bases should be constantly taken into account in our research and should be understood for what protection and safety are generally needed. During our research, we have always taken into account the fundamental aspects of the very essence of security and defense as such.

How security works and how it is managed is described in the works of $\mathrm{Wu}$ et al. [12-14]. It is impossible to build any functional model or describe any process related to safety without understanding how this process works. Realizing this, we have formed our own methodological approach to the formation of a defense ecosystem in the context of ensuring homeland security.

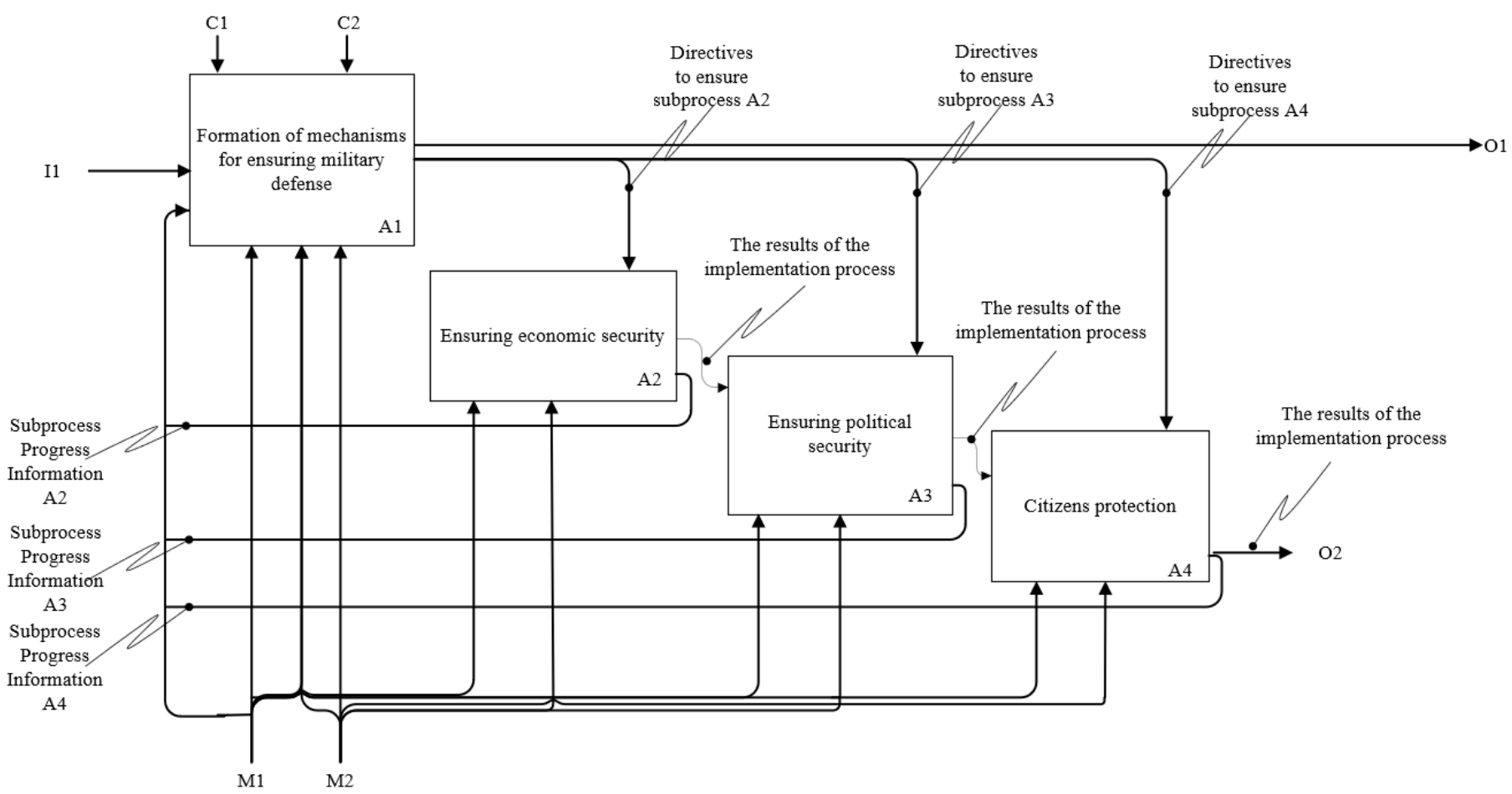

Figure 3. Decomposition of the first level of the context diagram of the IDEF0 model of the defense ecosystem in the context of ensuring homeland security (developed by authors) 


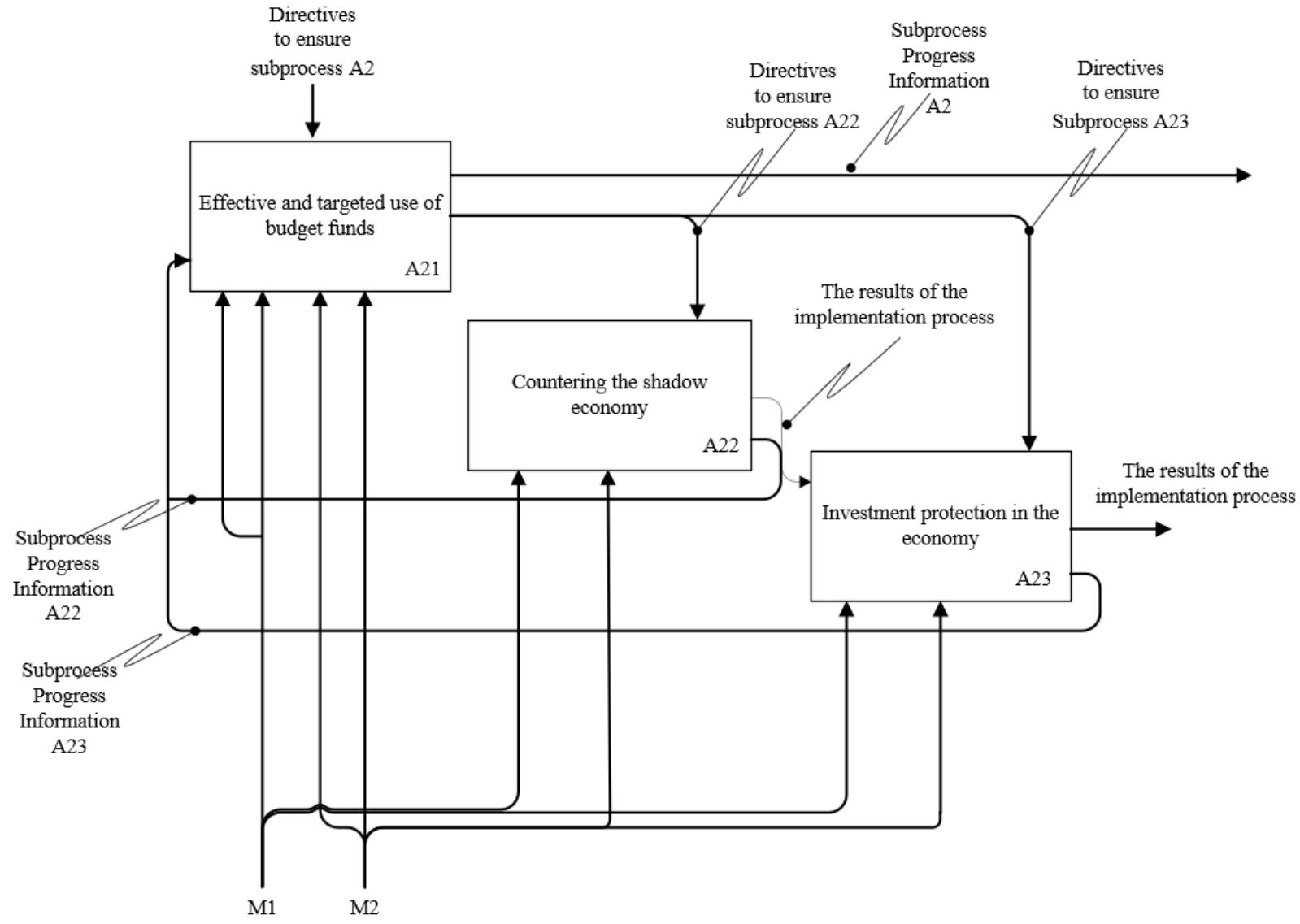

Figure 4. Decomposition of the second level of the context diagram of the IDEF0 model of the defense ecosystem in the context of ensuring homeland security (developed by authors)

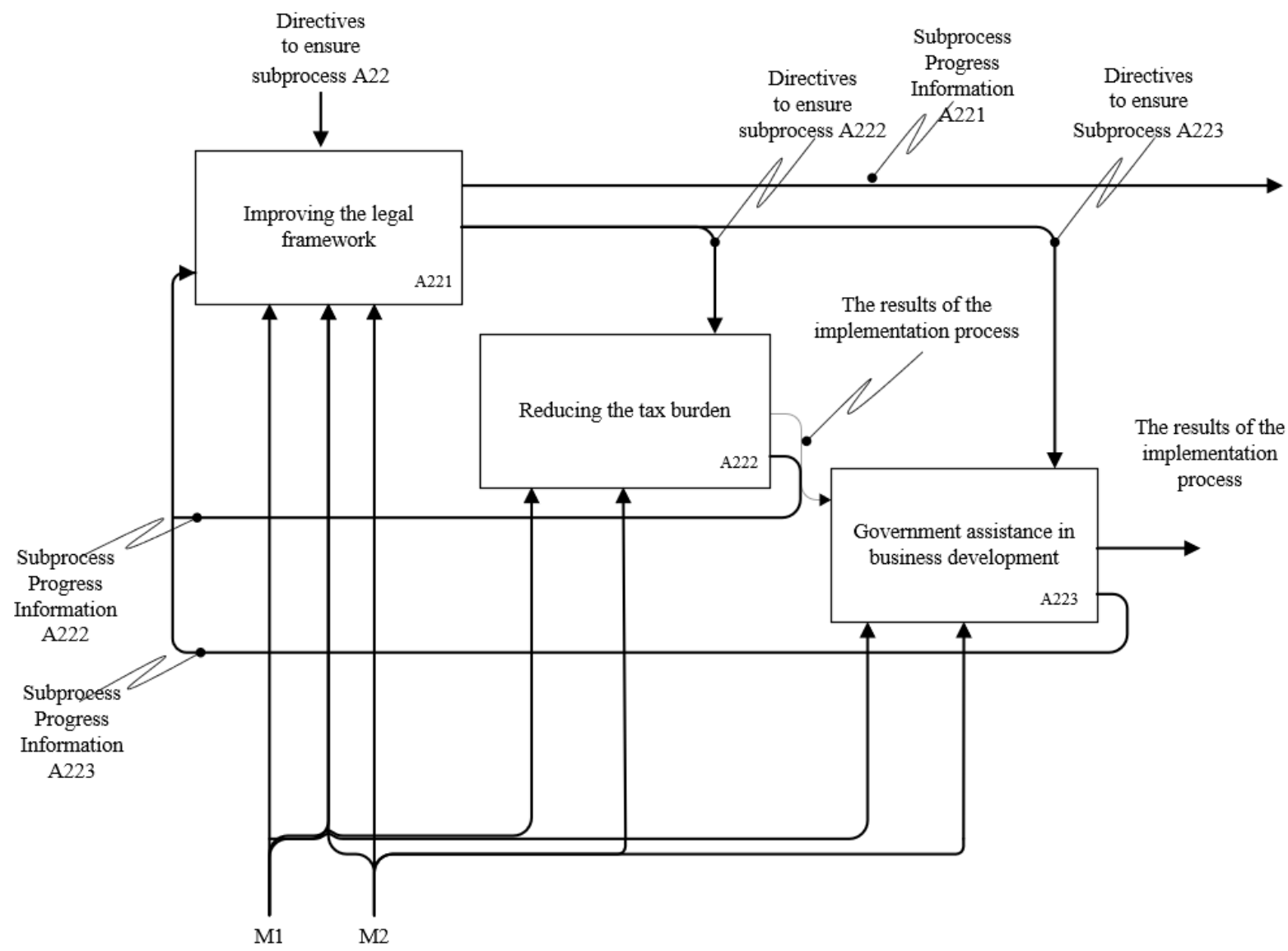

Figure 5. Decomposition of the third level of the context diagram of the IDEF0 model of the defense ecosystem in the context of ensuring homeland security (developed by authors) 
Our research may, to some extent, be part of the proposed security reform. But despite this, our research results became the formation of a decomposition of the first, second, and third levels of the functional model of the defense ecosystem in the context of ensuring homeland security $[15,16]$. A methodological approach can be of practical importance for state structures dealing with the issue of ensuring the homeland security. Its obviousness for application in practice means that it is for such structures that, in our opinion, it will be most effective.

\section{CONCLUSIONS}

The main result of our research was to propose a new methodological approach to the formation of the defense ecosystem in the context of ensuring homeland security, and as a result, we presented in decompositions how this can be achieved and what aspects should be paid attention to. Each decomposition has several concretizing elements and stages that allow one or another subsystem to be achieved, depending on what level it is.

To argue that we have proposed a methodological approach to the formation of an environmental ecosystem in the context of the formation of family security, based on the use of the IDEF0 methodology for such an area as security and demonstrating a consistent process of its application.

Thus, by homeland security we mean an indicator of the ability of society and the state, protecting national interests, independently or together with other friendly countries (peoples, nations), to contain or eliminate internal and external threats to national sovereignty, territorial integrity, social order, and economic development, other important elements of spiritual and material life; the degree of protection of the interests of the individual, society, and the state from external and internal threats. Ensuring homeland security contributes to the peaceful nature of the relationship of the state (people, nation) with other states (peoples, nations). Strengthening homeland security consists in creating the conditions necessary for the reliable protection of the interests of the state and the nation and the successful solution of political, economic, social, and other tasks facing them.

Ensuring security is a complex process and building a proper ecosystem, too. We have proven the importance of researching the defense ecosystem in the context of ensuring homeland security.

An important role in solving many socio-political problems, including those related to security, is played by political authority, the authority of the authorities. This factor is especially actualized in the conditions of transitional societies when trust in the authorities can become a consolidating moment in the life of society and contribute to the maximum implementation of existing mechanisms for ensuring homeland security. The government, which has the support and recognition of the majority of citizens, can more effectively neutralize and solve emerging problems, and influence the processes that pose a threat. With the help of the authority of the authorities, political institutions (primarily those of them directly related to activities in the field of security), and the person performing political functions, a nonviolent influence on the participants in the events is provided.

As a result, four key areas have identified that form the defense ecosystem in the context of ensuring homeland security: economic, political, social, and military. Each of them, thanks to the use of functional modeling, found its place in the proposed IDEF0 model in the presented decomposition of the first level. To detail individual areas, as the example given, a decomposition of the second level was presented with a detailed description of actions for a specific area of the forming defense ecosystem.

The article has limitations and they are associated with the choice of the security system of Ukraine since in the context of a pandemic, it was difficult to gain access to information from other countries. In the future, the proposed methodological approach is planned to be applied to the security systems of other countries.

\section{REFERENCES}

[1] Hrybinenko, O., Bulatova, O., Zakharova, O. (2020). Evaluation of demographic component of countries' economic security. Business, Management and Economics Engineering, 18(2): 307-330. https://doi.org/10.3846/jbem.2020.12309

[2] Borodzicz, E.P., Gibson, S.D. (2006). Corporate security education: Towards meeting the challenge. Security Journal, 19(3): 180-195. https://doi.org/10.1057/palgrave.sj.8350016

[3] Baldwin, D. (1997). The concept of security. Review of International Studies, 23: 5-26. https://doi.org/10.1017/S0260210597000053

[4] Kryshtanovych, M., Petrovskyi, P., Khomyshyn, I., Bezena, I., Serdechna, I. (2020). Peculiarities of implementing governance in the system of social security. Business, Management and Economics Engineering, 18(1): 142-156. https://doi.org/10.3846/bme.2020.12177

[5] Kryshtanovych, M., Akimova, L., Akimov, O., Kubiniy, N., Marhitich, V. (2021). Modeling the process of forming the safety potential of engineering enterprises. International Journal of Safety and Security Engineering, 11(3): 223-230. https://doi.org/10.18280/ijsse.110302

[6] Browning, C. (2013) Interhomeland Security: A Very Short Introduction. Oxford University Press, Oxford

[7] Patel, K., Chudasama, D. (2021). Homeland security Threats in Cyberspace. National Journal of Cyber Security Law, 4(1): 12-20.

[8] Balzacq, T. (2011). Securitization theory. How Security Problems Emerge and Dissolve (Peace Research Institute Oslo (PRIO) New Security Studies), London.

[9] Alseraidi, S.M. (2009). USA Homeland Security: A Model for the United Arab Emirates. ARMY WAR COLL CARLISLE BARRACKS PA

[10] Munro, D. (2010). Homeland Security: Assessing the First Five Years. Philadelphia: University of Pennsylvania Press.

[11] Zedner, L. (2003). Too much security. International Journal of the Sociology of Law, 31(3): 155-184. https://doi.org/10.1016/j.ijsl.2003.09.002

[12] Wu, Y., Meng, F. (2019). Security classification for safe management and information resource. Journal of $\begin{array}{llll}\text { Strategic } & \text { Security, } & \text { 11(4): }\end{array}$ https://doi.org/10.5038/1944-0472.11.4.1694

[13] Kachynsky, A.B. (2013). Indicators of the homeland security: Determination and use of their boundary values. NISR.

[14] Onischenko, V.O. (2011). Theoretical aspects of security formation. Economy and Region: Sciences. Hanging, 
4(31): 3-9. https://doi.org/10.32702/2307-21562019.11.38

[15] Reichenstein, W. (2019). Security reforms. The Journal of Retirement, 6(4): 30-44. https://doi.org/10.3905/jor.2019.1.051

[16] Sylkin, O., Kryshtanovych, M., Zachepa, A., Bilous, S.,
Krasko, A. (2019). Modeling the process of applying anti-crisis management in the system of ensuring financial security of the enterprise. Business: Theory and Practice, 20:

https://doi.org/10.3846/btp.2019.41 446-455. 